\title{
Article \\ Effect of Microcapsules of a Waterborne Core Material on the Properties of a Waterborne Primer Coating on a Wooden Surface
}

\author{
Xiaoxing Yan ${ }^{1,2, *}$ and Wenwen Peng ${ }^{2}$ \\ 1 Co-Innovation Center of Efficient Processing and Utilization of Forest Resources, Nanjing Forestry University, \\ Nanjing 210037, China \\ 2 College of Furnishings and Industrial Design, Nanjing Forestry University, Nanjing 210037, China; \\ yjsww@njfu.edu.cn \\ * Correspondence: yanxiaoxing@njfu.edu.cn; Tel.: +86-25-85427528
}

Citation: Yan, X.; Peng, W. Effect of Microcapsules of a Waterborne Core Material on the Properties of a Waterborne Primer Coating on a Wooden Surface. Coatings 2021, 11, 657. https://doi.org/10.3390/ coatings11060657

Academic Editor:

Ioannis Karapanagiotis

Received: 7 May 2021

Accepted: 28 May 2021

Published: 30 May 2021

Publisher's Note: MDPI stays neutral with regard to jurisdictional claims in published maps and institutional affiliations.

Copyright: (c) 2021 by the authors. Licensee MDPI, Basel, Switzerland. This article is an open access article distributed under the terms and conditions of the Creative Commons Attribution (CC BY) license (https:// creativecommons.org/licenses/by/ $4.0 /)$.

\begin{abstract}
Microcapsules of a waterborne core material were prepared using a waterborne primer. The microcapsules of the waterborne core material were added to the waterborne primer to explore the effects of different core-shell ratios and mass fractions of the microcapsules on the property of the waterborne primer coating on the wooden surface. The results show that as the mass fraction of the microcapsules increased, the chromatic aberration increased by degrees, the glossiness decreased gradually, and the hardness increased by degrees, whilst-except for the coating with 0.50:1 microcapsules-the adhesion decreased gradually. When the mass fraction of the microcapsules increased, the impact resistance increased first and decreased later, or remained unchanged after reaching a certain value. When the mass fraction of the microcapsules increased, the elongation at the break increased first and decreased later. When the core-shell ratio was small and the mass fraction was between $5.0 \%$ and $15.0 \%$, the coating had better liquid resistance. When the core-shell ratio was $0.67: 1$ and the mass fraction was $10.0 \%$, the overall property of the coating on the Basswood was the best. The technology of microencapsulation provides a technical reference for the waterborne primer with self-repair qualities on the surface of wooden products.
\end{abstract}

Keywords: microcapsule; waterborne primer; coating

\section{Introduction}

Self-repairing microcapsules can inhibit the micro-cracks on the coating. When the coating cracks, the core material of the microcapsule repairs the cracks. Microencapsulation technology has been used in many technical fields [1-3]. Cotting et al. [4] synthesized polyurea-formaldehyde melamine microcapsules by in-situ polymerization. The results show that the coating of microcapsules has a remarkable self-healing effect when it is subjected to mechanical defect stress. The microcapsules with high concentrations (15 wt. \%) have a better self-healing ability and better corrosion resistance properties. Tzavidi et al. [5] prepared polyurea-formaldehyde (UF)-coated epoxy resin microcapsules, and studied the effects of different technological parameters on the properties of the microcapsules. The coverage rate of the core material was between 65 and 77\%. Sun et al. [6] reported the preparation of metal-shell microcapsules, providing a good technical reference to improve the microcapsules' robustness. Studies have shown that the coating added to the microcapsules has good anticorrosive properties in salty water. Jiang et al. [7] reported the preparation of self-healing and flame-retardant microcapsules by the phacoemulsification-solvent volatilization method. The results show that SFRM has a large particle size distribution and thermal stability, and sustained-release and flame-retardant properties. The repair rate was about $61 \%$. Ning et al. [8] investigated the effect of the initiator concentration, microcapsule size and concentration on the self-healing properties. The results show that the fracture toughness of the composites increases significantly as the microcapsule size and concentration increases. The self-healing efficiency of the microcapsules was the highest, reaching 
$76 \%$. In our previous study [9], the preparation of the epoxy resin microcapsules by in situ polymerization was reported, and the yield, coverage rate, repair rate and morphology of the microcapsules were studied. The results showed that the microcapsules have a self-healing effect, and the self-healing efficiency can reach $114.77 \%$.

Wood coating is a new type of coating, which has the advantages of environmental protection, pollution resistance, low cost and being fast drying [10,11]. It can not only stabilize the performance of wooden materials but also has the functions of anti-corrosion, being flame retardant and fragrance retention $[12,13]$. Among them, waterborne coatings are very popular in the field of wooden surface coating [14,15]. In this paper, Basswood was used as the base material, and wood waterborne primer was used as the paint base. The waterborne primer is in direct contact with the wood in order to protect the wood substrate and combine well with the waterborne topcoat, and the performance of the primer is required to be higher, so the performance of the waterborne primer with microcapsules was studied. Seven kinds of microcapsules were added into the waterborne primer coatings to test the optical performance [16-18], mechanical properties [19-21], liquid resistance [22], the micro-morphology [23-25] and chemical composition [26-28] of the coatings. At the same time, the influence of different microcapsules on the performance of the waterborne primer coating was investigated.

\section{Materials and Methods}

\subsection{Experimental Materials}

The triethanolamine $\left(\mathrm{M}_{\mathrm{w}}: 149.19 \mathrm{~g} / \mathrm{mol}\right.$, CAS No.: 102-71-6), urea $\left(\mathrm{M}_{\mathrm{w}}: 60.06 \mathrm{~g} / \mathrm{mol}\right.$, CAS No.: 57-13-6) and formaldehyde solution (37\%, $\mathrm{M}_{\mathrm{w}}: 30.03 \mathrm{~g} / \mathrm{mol}$, CAS No.: 50-00-0) were supplied by Guangzhou Jiangshun Chemical Technology Co., Ltd., Guangzhou, China. The N-octanol $\left(\mathrm{M}_{\mathrm{w}}: 130.23 \mathrm{~g} / \mathrm{mol}\right.$, CAS No.: 111-87-5) was provided by Nantong Wanrong International Trade Co., Ltd., Nantong, China. The citric acid monohydrate $\left(\mathrm{M}_{\mathrm{w}}: 210.14 \mathrm{~g} / \mathrm{mol}\right.$, CAS No.: 5949-29-1) and sodium dodecyl benzene sulfonate $\left(\mathrm{M}_{\mathrm{w}}\right.$ : 348.48 g/mol, CAS No.: 25155-30-0) were provided by Jiading Chemical Technology Co., Ltd., Suzhou, China. The waterborne primer was supplied by Nippon Paint Co., Ltd., Guangzhou, China. The Basswood $(120 \mathrm{~mm} \times 75 \mathrm{~mm} \times 5 \mathrm{~mm})$ was supplied by Suqian Qingyun Wood Industry Co. Ltd., Suqian, China.

\subsection{Experimental Method}

In order to prepare microcapsules according to Table 1, the shell of the material was first prepared. In total, $20.0 \mathrm{~g}$ urea and $27.0 \mathrm{~g} \mathrm{37 \%}$ formaldehyde solution were mixed and stirred at $300 \mathrm{rpm}$. Then, triethanolamine was slowly added to adjust the $\mathrm{pH}$ value of the solution to 9.0 and stirred continuously at $60^{\circ} \mathrm{C}$ for $80 \mathrm{~min}$.

Table 1. Proportion of the raw materials.

\begin{tabular}{ccccccc}
\hline Sample & Urea (g) & $\begin{array}{c}\text { Formaldehyde } \\
\text { Solution (g) }\end{array}$ & $\begin{array}{c}\text { Waterborne } \\
\text { Acrylic } \\
\text { Coating (g) }\end{array}$ & $\begin{array}{c}\text { Sodium Dodecyl } \\
\text { Benzene } \\
\text { Sulfonate (g) }\end{array}$ & $\begin{array}{c}\text { Deionized } \\
\text { Water (g) }\end{array}$ & $\begin{array}{c}\text { Core-Shell } \\
\text { Ratio }\end{array}$ \\
\hline 1 & 20.0 & 27.0 & 12.5 & 0.98 & 97.02 & $0.42: 1$ \\
2 & 20.0 & 27.0 & 15.0 & 1.17 & 115.83 & $0.50: 1$ \\
3 & 20.0 & 27.0 & 17.5 & 1.37 & 135.60 & $0.58: 1$ \\
4 & 20.0 & 27.0 & 20.0 & 1.56 & 154.44 & $0.67: 1$ \\
5 & 20.0 & 27.0 & 22.5 & 1.76 & 174.24 & $0.75: 1$ \\
6 & 20.0 & 27.0 & 25.0 & 1.95 & 193.05 & $0.83: 1$ \\
7 & 20.0 & 27.0 & 27.5 & 2.15 & 212.85 & $0.92: 1$ \\
\hline
\end{tabular}

In order to prepare the core material emulsion, the waterborne primer was mixed with a $1.0 \%$ aqueous solution of sodium dodecyl benzene sulfonate via magnetic stirring (1200 rpm) for $30 \mathrm{~min}$ at $70{ }^{\circ} \mathrm{C}$.

At room temperature, the shell of the material was slowly dropped into the core material at $300 \mathrm{rpm}$ and citric acid monohydrate crystal was added gradually to adjust the 
$\mathrm{pH}$ to 3-4. Then, the reaction temperature was raised to $60^{\circ} \mathrm{C}$ for $2 \mathrm{~h}$. The mixture was left to rest for 5 days and then filtrated. After that, the product was put into a drying box for $4 \mathrm{~h}$ at $80^{\circ} \mathrm{C}$ and, eventually, white powder microcapsules were obtained.

As can be seen in Table 2, different amounts of microcapsules were added into the waterborne primer to give mixtures with mass fractions of microcapsules of $0,5.0 \%, 10.0 \%$, $15.0 \%, 20.0 \%$ and $25.0 \%$. The prepared coating mixtures were spread onto substrate once, in a single layer, and left to dry for $30 \mathrm{~min}$. Then, the samples were heated in a $40{ }^{\circ} \mathrm{C}$ drying oven until the mass no longer changed. The dried coatings were placed outside the oven, naturally cooled, gently polished with fine sandpaper and then wiped with a dry and clean cloth. The above steps were repeated twice. The whole experimental process is shown in Figure 1.

Table 2. Ingredients for the preparation of the waterborne primer coatings.

\begin{tabular}{cccc}
\hline $\begin{array}{c}\text { Mass Fraction of } \\
\text { Microcapsules (\%) }\end{array}$ & $\begin{array}{c}\text { Mass of Microcapsules } \\
\text { (g) }\end{array}$ & $\begin{array}{c}\text { Mass of Waterborne } \\
\text { Primer (g) }\end{array}$ & $\begin{array}{c}\text { Mass of Self-Healing } \\
\text { Waterborne Primer (g) }\end{array}$ \\
\hline 0 & 0 & 4.0 & 4.0 \\
5.0 & 0.2 & 3.8 & 4.0 \\
10.0 & 0.4 & 3.6 & 4.0 \\
15.0 & 0.6 & 3.4 & 4.0 \\
20.0 & 0.8 & 3.2 & 4.0 \\
25.0 & 1.0 & 3.0 & 4.0 \\
\hline
\end{tabular}

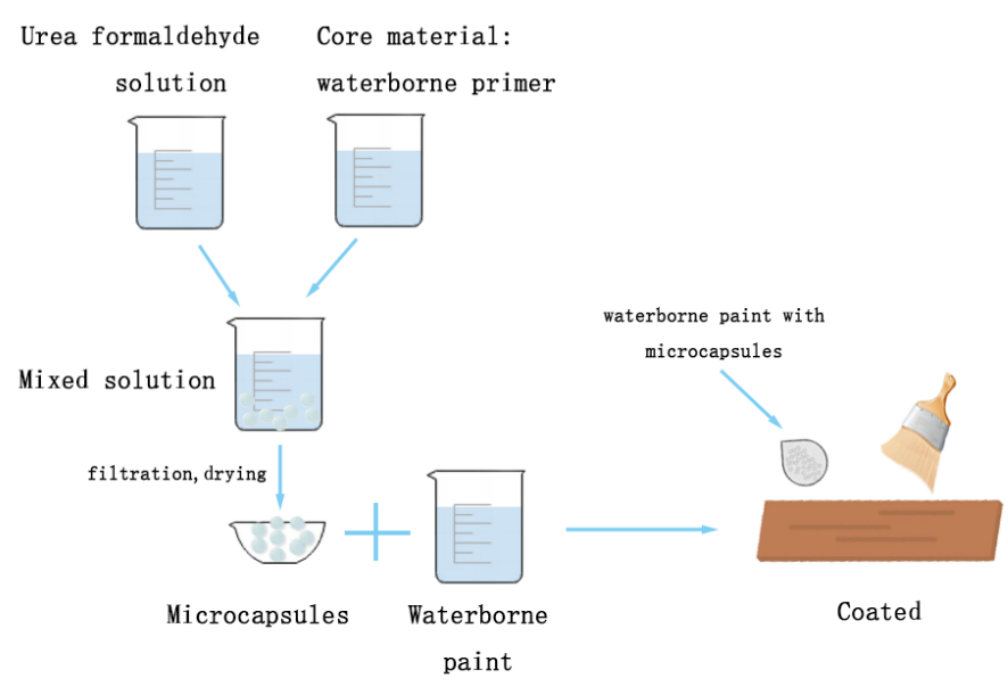

Figure 1. Flow chart of the experiment.

\subsection{Testing and Characterization}

The portable chromatic aberration meter (Hefei Nian Qing Power Equipment Co., Ltd., Hefei, China) was used to test the chromatic aberration. The $60^{\circ}$ glossiness of the coatings was tested using an LS191 intelligent gloss meter (Shenzhen Linshang Technology Co., Ltd., Shenzhen, China). The hardness of the coatings was measured using a pencil hardness tester (Beijing Wowei Technology Co., Ltd., Beijing, China).

The adhesion of the coatings was measured using a F107 film scriber (Beijing Times Jiaxiang Technology Co., Ltd., Beijing, China). The adhesion of the coating was tested according to the national standard GB/T 4893.4-2013 "Test of surface coatings of furniturePart 4: Determination of adhesion-Cross cut" [29]. The cutting tool was perpendicular to the surface of the sample and the cut on the paint coating was made at a uniform rate. All of the cutting was to the surface of the substrate. Then, the surface was rotated $90^{\circ}$ in the original direction to cut to form a grid pattern. The grid pattern was brushed lightly with a brush, and the tape was stuck on the grid pattern to make the tape fully contact with the paint coating. Then, as close as possible to $60^{\circ}$, the adhesive tape was torn off smoothly within $0.5 \mathrm{~s}-1.0 \mathrm{~s}$, and the peeling of the paint coating on the tape was observed. 
The impact resistance of the coatings was tested using a film impact tester (Dongguan Daxian Automation Equipment Co., Ltd., Dongguan, China). According to the standard GB/T4893.9-2013 "Determination of impact resistance of film" [30], the test board was placed on the iron paste embedded in the seat of the impact testing machine, and a heavy hammer was fixed to a certain height. When the control button was pressed, the heavy hammer fell freely onto the test board. We took out the test board and observed whether there are cracks and spalling on the surface of the test board.

The elongation at the break of the coatings was measured using a universal mechanical testing machine (Shandong Kaifeng Testing Technology Co., Ltd., Jinan, China). During the test, we clamped the two ends of the coating to ensure that the coating will not slide. The coating deformed at a tensile speed of $0.12 \mathrm{~mm} / \mathrm{min}$ and broke under a certain longitudinal load. The elongation at the break = the coating elongation/ the original length of the coating between clamps $\times 100 \%$.

The liquid resistance of the coatings was tested against $15 \% \mathrm{NaCl}, 70 \%$ medical ethanol (Nanjing Shenghinghe Chemical Co. Ltd., Nanjing, China), detergent (LIbY Group Co., Ltd., Guangzhou, China) and red ink (Shanghai Hero Co., Ltd., Shanghai, China). The filter paper was put into the test solution to soak for $30 \mathrm{~s}$. It was then placed on the test board with tweezers. Then, the sample was covered with a glass cover. After 1 day, we removed the glass cover and filter paper and dried the residual liquid on the surface of the test plate with absorbent paper and let sample stand for $30 \mathrm{~min}$. Then, we checked the damage of the experimental area of the sample for marks and discoloration. The chromatic aberration and glossiness of each test board were measured to judge the influence of the different reagents on the coating performance.

The microstructure and chemical composition of the coatings were assessed using a Quanta-200 scanning electron microscope (FEI Co., Ltd., Hillsboro, OR, USA), a Zeiss Axioscope 5 Optical Microscope (SPECTRO Co., Ltd., Germany) and a FTIR-850 infrared spectrum analyzer (Tianjin Gangdong Science and Technology Development Co., Ltd., Tianjin, China). All of the tests were repeated five times with a standard error of less than $5 \%$.

\section{Results and Discussion}

\subsection{Effect of the Microcapsules on the Optical Properties of the Coatings}

\subsubsection{Chromatic Aberration}

$\mathrm{L}_{1}, \mathrm{a}_{1}$ and $\mathrm{b}_{1}$ are the chromaticity values at one point on the coating, while $\mathrm{L}_{2}$, $\mathrm{a}_{2}$ and $b_{2}$ are the chromatic values of the other point. According to the formula: $\Delta \mathrm{L}$ (brightness difference) $=\mathrm{L}_{1}-\mathrm{L}_{2}, \Delta \mathrm{a}$ (red-green color difference) $=\mathrm{a}_{1}-\mathrm{a}_{2}, \Delta \mathrm{b}$ (yellow-blue color difference) $=b_{1}-b_{2}$, and the chromatic aberration value is calculated by formula (1):

$$
\Delta \mathrm{E}=\left[(\Delta \mathrm{L})^{2}+(\Delta \mathrm{a})^{2}+(\Delta \mathrm{b})^{2}\right]^{1 / 2}
$$

The influence of the microcapsules on the chromatic aberration of the primer coating is shown in Figure 2. Under the same core-shell ratio, the chromatic aberration of the coating increased by degrees. The uneven color observed on the coatings is due most likely to the increase of the white particle content. When the mass fractions of the microcapsules was $0-10.0 \%$, the color of the coating basically did not change, and the chromatic aberration range was 1.0-2.1. 


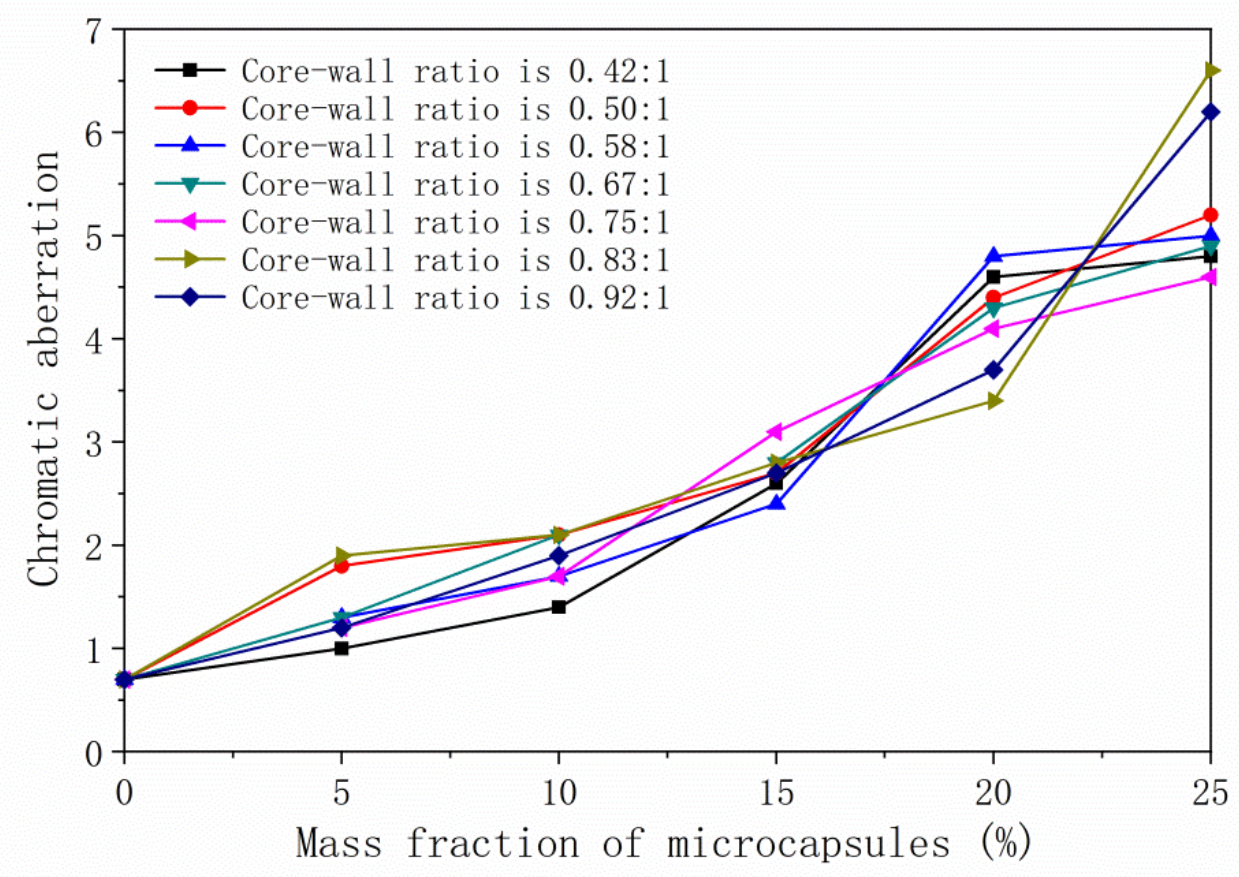

Figure 2. The chromatic aberration of the coatings.

\subsubsection{Glossiness}

It can be seen from Figure 3 that the glossiness of the coating decreased by degrees at the same core-shell ratio. When the mass fraction of the microcapsules increased to $5.0 \%$, the glossiness of the coating decreased from $18.7 \%$ to $12.1-15.2 \%$. When the mass fraction of the microcapsules continued to increase to $10.0 \%$, the glossiness of the coating decreased to the range of $7.6-10.7 \%$. This was due to the increase of the microcapsule content when the roughness of the coating became larger and the surface particles became greater, which led to an enhanced diffuse reflection and, consequently, the reduced glossiness of the coatings.

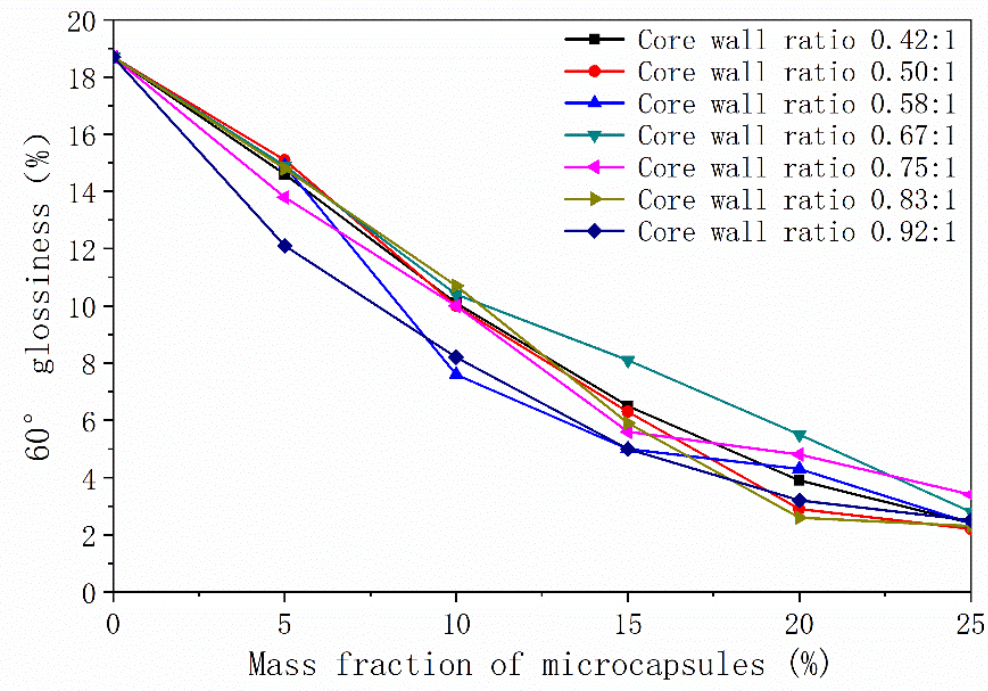

Figure 3. The glossiness of the coatings.

3.2. Effect of the Microcapsules on the Mechanical Properties of the Coatings

\subsubsection{Hardness}

The hardness test results are shown in Table 3. Under the same core-shell ratio, the hardness of the coating increased by degrees, except for the 0.50:1 microcapsules, for which 
the hardness increased when the mass fraction changed from 0 to $15.0 \%$ and then decreased with the increase of the microcapsule content above $15.0 \%$. The latter behavior could be explained by the uneven distribution of the microcapsules as their content gradually increased, giving a weak ability to resist external destructive force [31,32]. Comparatively, there were no significant differences in the hardness of the coatings with the same mass fraction of microcapsules. Combined with the optical performance test results, the hardness of the coating was better when the core-shell ratios of the microcapsules were 0.58:1 and $0.67: 1$, and the mass fractions of microcapsules were $10.0-15.0 \%$.

Table 3. The hardness of the coatings.

\begin{tabular}{|c|c|c|c|c|c|c|c|}
\hline \multirow{3}{*}{$\begin{array}{l}\text { Mass Fraction of } \\
\text { Microcapsules }(\%)\end{array}$} & \multicolumn{7}{|c|}{ Hardness } \\
\hline & Core-Shell & Core-Shell & Core-Shell & Core-Shell & Core-Shell & Core-Shell & Core-Shell \\
\hline & Ratio 0.42:1 & Ratio 0.50:1 & Ratio 0.58:1 & Ratio 0.67:1 & Ratio 0.75:1 & Ratio 0.83:1 & Ratio 0.92:1 \\
\hline 0 & $\mathrm{HB}$ & НВ & HB & $\mathrm{HB}$ & $\mathrm{HB}$ & $\mathrm{HB}$ & $\mathrm{HB}$ \\
\hline 5.0 & $2 \mathrm{H}$ & $2 \mathrm{H}$ & $2 \mathrm{H}$ & $2 \mathrm{H}$ & $\mathrm{H}$ & $2 \mathrm{H}$ & $2 \mathrm{H}$ \\
\hline 10.0 & $2 \mathrm{H}$ & $2 \mathrm{H}$ & $3 \mathrm{H}$ & $3 \mathrm{H}$ & $2 \mathrm{H}$ & $2 \mathrm{H}$ & $2 \mathrm{H}$ \\
\hline 15.0 & $3 \mathrm{H}$ & $3 \mathrm{H}$ & $3 \mathrm{H}$ & $3 \mathrm{H}$ & $2 \mathrm{H}$ & $2 \mathrm{H}$ & $2 \mathrm{H}$ \\
\hline 20.0 & $3 \mathrm{H}$ & $2 \mathrm{H}$ & $3 \mathrm{H}$ & $3 \mathrm{H}$ & $3 \mathrm{H}$ & $3 \mathrm{H}$ & $3 \mathrm{H}$ \\
\hline 25.0 & $3 \mathrm{H}$ & $2 \mathrm{H}$ & $4 \mathrm{H}$ & $4 \mathrm{H}$ & $3 \mathrm{H}$ & $3 \mathrm{H}$ & $3 \mathrm{H}$ \\
\hline
\end{tabular}

\subsubsection{Adhesion}

The test results of the coating adhesion are shown in Table 4 . The results show that the adhesion of the coating decreased gradually at the same core-shell ratio. The coatings with core-shell ratios of $0.58: 1$ and $0.67: 1$ have the best overall adhesion. When the mass fractions of the microcapsules were $0-5.0 \%$, the adhesion was the best, which was level 0 . When the mass fractions were $10.0-20.0 \%$, the coating had good adhesion, which was level 1 . When the mass fraction reached $25.0 \%$, the adhesion of the coating was poor, which was level 2. This is because the adhesion is caused by the interaction between the polymer in the coating and the polar radical on the surface of the Basswood [33,34]. The increase of the microcapsules results in the deterioration of the force between the coating and the wood. Overall, the coatings with the core-shell ratios of 0.58:1 and 0.67:1 had the best overall adhesion. At these two core-shell ratios, when the mass fraction of microcapsules was $0-20.0 \%$, the adhesion of the coating was better.

Table 4. The adhesion of the coatings.

\begin{tabular}{|c|c|c|c|c|c|c|c|}
\hline \multirow{2}{*}{$\begin{array}{c}\text { Mass } \\
\text { Fraction of } \\
\text { Microcap- } \\
\text { sules }\end{array}$} & \multicolumn{7}{|c|}{ Adhesion (Level) } \\
\hline & $\begin{array}{l}\text { Core-Shell } \\
\text { Ratio 0.42:1 }\end{array}$ & $\begin{array}{l}\text { Core-Shell } \\
\text { Ratio 0.50:1 }\end{array}$ & $\begin{array}{l}\text { Core-Shell } \\
\text { Ratio 0.58:1 }\end{array}$ & $\begin{array}{l}\text { Core-Shell } \\
\text { Ratio 0.67:1 }\end{array}$ & $\begin{array}{l}\text { Core-Shell } \\
\text { Ratio 0.75:1 }\end{array}$ & $\begin{array}{l}\text { Core-Shell } \\
\text { Ratio 0.83:1 }\end{array}$ & $\begin{array}{l}\text { Core-Shell } \\
\text { Ratio 0.92:1 }\end{array}$ \\
\hline$(\%)$ & 0 & 0 & 0 & 0 & 0 & 0 & 0 \\
\hline 5.0 & 0 & 1 & 0 & 0 & 1 & 0 & 1 \\
\hline 10.0 & 1 & 1 & 1 & 1 & 1 & 1 & 1 \\
\hline 15.0 & 1 & 1 & 1 & 1 & 1 & 1 & 2 \\
\hline 20.0 & 2 & 2 & 1 & 1 & 2 & 2 & 2 \\
\hline 25.0 & 3 & 2 & 2 & 2 & 2 & 3 & 2 \\
\hline
\end{tabular}

\subsubsection{Impact Resistance}

As shown in Table 5, at the same core-shell ratio, the impact resistance increased first and decreased later, or remained unchanged after being enhanced to a certain value. When the mass fraction of the microcapsule increased, it is more favorable to the stress transfer between particle and matrix, and the loading capacity becomes stronger. However, when the mass fraction of the microcapsules was enhanced to a certain value, the uneven particles on the coating led to the change of the impact resistance. The results show that when the mass fractions of the microcapsules were $10.0-20.0 \%$, the impact resistance of the coating was stronger. 
Table 5. The impact resistance of the coatings.

\begin{tabular}{|c|c|c|c|c|c|c|c|}
\hline \multirow{2}{*}{$\begin{array}{c}\text { Mass } \\
\text { Fraction of } \\
\text { Microcap- } \\
\text { sules }\end{array}$} & \multicolumn{7}{|c|}{ Impact Resistance $(\mathrm{kg} \cdot \mathrm{cm})$} \\
\hline & $\begin{array}{l}\text { Core-Shell } \\
\text { Ratio 0.42:1 }\end{array}$ & $\begin{array}{l}\text { Core-Shell } \\
\text { Ratio 0.50:1 }\end{array}$ & $\begin{array}{l}\text { Core-Shell } \\
\text { Ratio 0.58:1 }\end{array}$ & $\begin{array}{l}\text { Core-Shell } \\
\text { Ratio 0.67:1 }\end{array}$ & $\begin{array}{l}\text { Core-Shell } \\
\text { Ratio 0.75:1 }\end{array}$ & $\begin{array}{l}\text { Core-Shell } \\
\text { Ratio 0.83:1 }\end{array}$ & $\begin{array}{l}\text { Core-Shell } \\
\text { Ratio 0.92:1 }\end{array}$ \\
\hline$(\%)$ & $6.0 \pm 0.5$ & $6.0 \pm 0.5$ & $6.0 \pm 0.5$ & $6.0 \pm 0.5$ & $6.0 \pm 0.5$ & $6.0 \pm 0.5$ & $6.0 \pm 0.5$ \\
\hline 5.0 & $8.0 \pm 0.8$ & $8.0 \pm 0.5$ & $8.0 \pm 0.8$ & $9.0 \pm 0.2$ & $9.0 \pm 0.1$ & $9.0 \pm 0.9$ & $8.0 \pm 0.7$ \\
\hline 10.0 & $9.0 \pm 0.1$ & $12.0 \pm 0.5$ & $9.0 \pm 0.8$ & $10.0 \pm 0.5$ & $10.0 \pm 0.8$ & $12.0 \pm 0.5$ & $12.0 \pm 0.5$ \\
\hline 15.0 & $10.0 \pm 0.8$ & $11.0 \pm 0.5$ & $10.0 \pm 0.5$ & $13.0 \pm 0.5$ & $10.0 \pm 0.5$ & $12.0 \pm 0.5$ & $10.0 \pm 0.5$ \\
\hline 20.0 & $12.0 \pm 0.5$ & $10.0 \pm 0.5$ & $13.0 \pm 0.5$ & $11.0 \pm 0.5$ & $11.0 \pm 0.5$ & $10.0 \pm 0.5$ & $10.0 \pm 0.5$ \\
\hline 25.0 & $9.0 \pm 0.8$ & $10.0 \pm 0.5$ & $13.0 \pm 0.5$ & $11.0 \pm 0.5$ & $11.0 \pm 0.5$ & $10.0 \pm 0.8$ & $10.0 \pm 0.5$ \\
\hline
\end{tabular}

\subsubsection{Elongation at the Break}

Combined with the above coating performance test results, the $0.42: 1,0.50: 1,0.58: 1$ and 0.67:1 microcapsules were added into the waterborne primer, and the elongation at the break is shown in Table 6. At the same core-shell ratio, the elongation at the break of the coating increased first and decreased later. The coating with a microcapsule coreshell ratio of $0.67: 1$ had the highest elongation at the break. When the mass fraction of the microcapsules increased from 0 to $15.0 \%$, the elongation at the break increased from $7.63 \%$ to $16.59 \%$. When the mass fraction of the microcapsules increased to $25.0 \%$, the elongation at the break decreased to $9.21 \%$. When the core-shell ratio of the microcapsules was $0.67: 1$ and the mass fraction of the microcapsules was $10.0-15.0 \%$, the coating had the best flexibility and the highest elongation at the break.

Table 6. The elongation at the break of the coatings.

\begin{tabular}{ccccc}
\hline \multirow{2}{*}{$\begin{array}{c}\text { Mass Fraction of } \\
\text { Microcapsules (\%) }\end{array}$} & Core-Shell Ratio & Core-Shell Ratio & Core-Shell Ratio & Core-Shell Ratio \\
\cline { 2 - 5 } & $\mathbf{0 . 4 2 : 1}$ & $\mathbf{0 . 5 0 : 1}$ & $\mathbf{0 . 5 8 : 1}$ & $\mathbf{0 . 6 7 : 1}$ \\
\hline 0 & $7.63 \pm 0.10$ & $7.91 \pm 0.10$ & $7.63 \pm 0.10$ & $7.63 \pm 0.10$ \\
5.0 & $8.20 \pm 0.30$ & $8.88 \pm 0.20$ & $10.16 \pm 0.10$ & $12.21 \pm 0.10$ \\
10.0 & $11.09 \pm 0.10$ & $10.25 \pm 0.20$ & $12.18 \pm 0.20$ & $16.59 \pm 0.10$ \\
15.0 & $12.25 \pm 0.20$ & $13.56 \pm 0.40$ & $14.18 \pm 0.10$ & $9.90 \pm 0.10$ \\
20.0 & $9.47 \pm 0.10$ & $9.28 \pm 0.20$ & $6.84 \pm 0.20$ & $9.21 \pm 0.10$ \\
25.0 & $7.52 \pm 0.30$ & & & \\
\hline
\end{tabular}

\subsection{Effect of the Microcapsules on the Liquid Resistance of the Coatings}

As shown in Table 7, after the $\mathrm{NaCl}$, ethanol and detergent resistance test, the chromatic aberration of the coatings was basically unchanged. After the red ink resistance test, the chromatic aberration did not change significantly, ranging from 0.4 to 4.0. As shown in Table 8, the glossiness had no change before and after the four liquid resistance tests.

Regarding the liquid resistance of the coating, grade 1 means no mark, grade 2 means a slight discoloration mark, grade 3 means a slight discoloration or obvious discoloration mark, and grade 4 means an obvious change, blister, or wrinkle, etc. From the results in Table 9, the liquid resistance to $\mathrm{NaCl}$ was grade 1 , and there was no mark. The liquid resistances to alcohol and detergent were basically grade 1 . However, when the microcapsules were increased, the liquid resistance grade for alcohol and detergent was poor, at grade $2-3$. The coating without microcapsules had a poor liquid resistance to red ink, which was grade 3 , with an obvious mark. When the microcapsules were increased, the liquid resistance of the coating to red ink gradually became worse. When the core-shell ratios of the microcapsules was $0.42: 1$ to $0.67: 1$, the liquid resistance of the coating to red ink was in the range of grade $1-3$. When the core-shell ratios of the microcapsules was $0.75: 1$ to $0.92: 1$, the liquid resistance to red ink was in the range of grade $2-3$. In conclusion, the liquid resistance was better when the core-shell ratio of the microcapsules was relatively small and the mass fraction of the microcapsules was $5.0-15.0 \%$. 
Table 7. Chromatic aberration of the waterborne primer coatings after the resistance to liquid test.

\begin{tabular}{|c|c|c|c|c|c|}
\hline \multirow{2}{*}{$\begin{array}{l}\text { Core-Shell Ratio of } \\
\text { Microcapsules }\end{array}$} & \multirow{2}{*}{$\begin{array}{l}\text { Mass Fraction of } \\
\text { Microcapsules (\%) }\end{array}$} & \multicolumn{4}{|c|}{ Chromatic Aberration } \\
\hline & & $\mathrm{NaCl}$ & Ethanol & Detergent & Red Ink \\
\hline \multirow{6}{*}{$0.42: 1$} & 0 & 1.0 & 0.9 & 1.1 & 3.0 \\
\hline & 5.0 & 1.0 & 0.7 & 0.6 & 1.4 \\
\hline & 10.0 & 1.1 & 0.6 & 1.1 & 0.8 \\
\hline & 15.0 & 0.7 & 0.8 & 1.0 & 0.8 \\
\hline & 20.0 & 1.1 & 0.4 & 0.8 & 1.1 \\
\hline & 25.0 & 0.7 & $8.8 \pm 0.1$ & 1.5 & $3.6 \pm 0.1$ \\
\hline \multirow{6}{*}{$0.50: 1$} & 0 & 1.0 & 0.9 & 1.1 & $3.0 \pm 0.1$ \\
\hline & 5.0 & 0.9 & $1.1 \pm 0.1$ & $1.1 \pm 0.1$ & $1.4 \pm 0.1$ \\
\hline & 10.0 & $1.1 \pm 0.1$ & 0.3 & 0.9 & 0.8 \\
\hline & 15.0 & 0.6 & 1.0 & 1.0 & $1.1 \pm 0.1$ \\
\hline & 20.0 & 1.0 & $1.7 \pm 0.1$ & $1.4 \pm 0.1$ & $2.9 \pm 0.1$ \\
\hline & 25.0 & 0.9 & $4.9 \pm 0.1$ & $1.5 \pm 0.1$ & $4.0 \pm 0.1$ \\
\hline \multirow{6}{*}{$0.58: 1$} & 0 & 1.0 & 0.9 & 1.1 & $3.0 \pm 0.1$ \\
\hline & 5.0 & 0.7 & 0.8 & 1.1 & 0.4 \\
\hline & 10.0 & 0.6 & 1.1 & 0.7 & $1.9 \pm 0.1$ \\
\hline & 15.0 & 0.7 & 1.0 & 1.0 & 1.0 \\
\hline & 20.0 & 1.0 & 0.5 & 0.7 & $2.5 \pm 0.1$ \\
\hline & 25.0 & 1.1 & $2.8 \pm 0.1$ & $2.4 \pm 0.1$ & $3.4 \pm 0.1$ \\
\hline \multirow{6}{*}{$0.67: 1$} & 0 & 1.0 & 0.9 & 1.1 & $3.0 \pm 0.1$ \\
\hline & 5.0 & 0.4 & 0.9 & $1.1 \pm 0.1$ & $1.5 \pm 0.1$ \\
\hline & 10.0 & 1.0 & 0.8 & 1.1 & 1.1 \\
\hline & 15.0 & 0.6 & 1.1 & 1.1 & $1.3 \pm 0.1$ \\
\hline & 20.0 & 0.9 & 0.4 & 1.0 & 0.6 \\
\hline & 25.0 & 1.0 & $2.7 \pm 0.1$ & 0.9 & $2.1 \pm 0.1$ \\
\hline \multirow{6}{*}{$0.75: 1$} & 0 & 1.0 & 0.9 & 1.1 & $3.0 \pm 0.2$ \\
\hline & 5.0 & 1.0 & 1.0 & 1.1 & $2.2 \pm 0.1$ \\
\hline & 10.0 & 0.7 & 0.4 & 0.4 & $2.3 \pm 0.1$ \\
\hline & 15.0 & $1.1 \pm 0.1$ & 0.6 & 0.5 & $2.2 \pm 0.1$ \\
\hline & 20.0 & 0.9 & 0.6 & 0.4 & $2.6 \pm 0.2$ \\
\hline & 25.0 & 1.0 & 1.0 & 1.0 & $2.8 \pm 0.1$ \\
\hline \multirow{6}{*}{$0.83: 1$} & 0 & $1.0 \pm 0.1$ & 0.9 & 1.1 & $3.0 \pm 0.1$ \\
\hline & 5.0 & 0.4 & 0.9 & 0.7 & $2.1 \pm 0.2$ \\
\hline & 10.0 & 0.9 & 0.5 & 0.4 & $2.1 \pm 0.1$ \\
\hline & 15.0 & $1.1 \pm 0.1$ & 0.3 & 0.2 & $2.2 \pm 0.1$ \\
\hline & 20.0 & $1.1 \pm 0.1$ & $4.3 \pm 0.2$ & $2.4 \pm 0.1$ & $2.2 \pm 0.2$ \\
\hline & 25.0 & $1.3 \pm 0.1$ & $8.2 \pm 0.1$ & $1.7 \pm 0.1$ & $3.4 \pm 0.1$ \\
\hline \multirow{6}{*}{$0.92: 1$} & 0 & 1.0 & 0.9 & $1.1 \pm 0.1$ & $3.0 \pm 0.1$ \\
\hline & 5.0 & 0.6 & $1.9 \pm 0.1$ & $1.1 \pm 0.1$ & $2.1 \pm 0.1$ \\
\hline & 10.0 & 0.6 & $1.6 \pm 0.1$ & 0.4 & $2.0 \pm 0.1$ \\
\hline & 15.0 & 0.4 & 0.7 & 0.4 & $2.2 \pm 0.1$ \\
\hline & 20.0 & 0.6 & $1.2 \pm 0.1$ & 0.9 & $2.5 \pm 0.2$ \\
\hline & 25.0 & 0.8 & $2.3 \pm 0.1$ & 0.9 & $3.1 \pm 0.1$ \\
\hline
\end{tabular}


Table 8. Glossiness of the waterborne primer coatings after the resistance to liquid test.

\begin{tabular}{|c|c|c|c|c|c|}
\hline \multirow{2}{*}{$\begin{array}{l}\text { Core-Shell Ratio of } \\
\text { Microcapsules }\end{array}$} & \multirow{2}{*}{$\begin{array}{l}\text { Mass Fraction of } \\
\text { Microcapsules (\%) }\end{array}$} & \multicolumn{4}{|c|}{ Glossiness (\%) } \\
\hline & & $\mathrm{NaCl}$ & Ethanol & Detergent & Red Ink \\
\hline \multirow{6}{*}{$0.42: 1$} & 0 & $18.5 \pm 0.4$ & $18.4 \pm 0.2$ & $18.7 \pm 0.3$ & $18.6 \pm 0.2$ \\
\hline & 5.0 & $14.2 \pm 0.2$ & $14.3 \pm 0.5$ & $14.8 \pm 0.5$ & $14.4 \pm 0.4$ \\
\hline & 10.0 & $9.6 \pm 0.3$ & $9.9 \pm 0.3$ & $9.8 \pm 0.2$ & $10.2 \pm 0.3$ \\
\hline & 15.0 & $5.7 \pm 0.1$ & $6.7 \pm 0.2$ & $6.2 \pm 0.3$ & $5.6 \pm 0.2$ \\
\hline & 20.0 & $3.5 \pm 0.1$ & $3.4 \pm 0.1$ & $3.7 \pm 0.1$ & $3.3 \pm 0.2$ \\
\hline & 25.0 & $2.1 \pm 0.1$ & $2.7 \pm 0.1$ & $2.3 \pm 0.1$ & $1.9 \pm 0.1$ \\
\hline \multirow{6}{*}{$0.50: 1$} & 0 & $18.5 \pm 0.5$ & $18.4 \pm 0.4$ & $18.7 \pm 0.5$ & $18.6 \pm 0.3$ \\
\hline & 5.0 & $15.2 \pm 0.3$ & $15.3 \pm 0.2$ & $15.1 \pm 0.3$ & $14.8 \pm 0.2$ \\
\hline & 10.0 & $10.1 \pm 0.2$ & $9.8 \pm 0.1$ & $10.2 \pm 0.1$ & $9.6 \pm 0.2$ \\
\hline & 15.0 & $6.1 \pm 0.1$ & $6.2 \pm 0.1$ & $6.0 \pm 0.1$ & $6.0 \pm 0.2$ \\
\hline & 20.0 & $2.9 \pm 0.1$ & $2.9 \pm 0.1$ & $2.7 \pm 0.1$ & $2.2 \pm 0.1$ \\
\hline & 25.0 & $2.1 \pm 0.1$ & $2.2 \pm 0.1$ & $2.1 \pm 0.1$ & $1.9 \pm 0.1$ \\
\hline \multirow{6}{*}{$0.58: 1$} & 0 & $18.5 \pm 0.3$ & $18.4 \pm 0.4$ & $18.7 \pm 0.5$ & $18.6 \pm 0.5$ \\
\hline & 5.0 & $14.6 \pm 0.7$ & $14.6 \pm 0.5$ & $14.9 \pm 0.4$ & $14.6 \pm 0.6$ \\
\hline & 10.0 & $7.9 \pm 0.2$ & $7.8 \pm 0.1$ & $7.5 \pm 0.1$ & $7.5 \pm 0.1$ \\
\hline & 15.0 & $5.0 \pm 0.0$ & $4.7 \pm 0.1$ & $4.9 \pm 0.1$ & $4.4 \pm 0.1$ \\
\hline & 20.0 & $4.0 \pm 0.1$ & $4.1 \pm 0.2$ & $4.3 \pm 0.2$ & $3.7 \pm 0.1$ \\
\hline & 25.0 & $2.2 \pm 0.1$ & $2.1 \pm 0.1$ & $2.2 \pm 0.1$ & $2.3 \pm 0.1$ \\
\hline \multirow{6}{*}{$0.67: 1$} & 0 & $18.5 \pm 0.5$ & $18.4 \pm 0.3$ & $18.7 \pm 0.4$ & $18.6 \pm 0.4$ \\
\hline & 5.0 & $13.3 \pm 0.3$ & $13.7 \pm 0.2$ & $13.5 \pm 0.3$ & $12.5 \pm 0.3$ \\
\hline & 10.0 & $9.3 \pm 0.2$ & $9.3 \pm 0.3$ & $9.2 \pm 0.3$ & $8.8 \pm 0.1$ \\
\hline & 15.0 & $8.1 \pm 0.2$ & $8.2 \pm 0.2$ & $8.2 \pm 0.3$ & $7.7 \pm 0.2$ \\
\hline & 20.0 & $5.4 \pm 0.1$ & $5.5 \pm 0.1$ & $5.5 \pm 0.2$ & $5.1 \pm 0.2$ \\
\hline & 25.0 & $2.5 \pm 0.2$ & $2.6 \pm 0.1$ & $2.8 \pm 0.2$ & $2.8 \pm 0.1$ \\
\hline \multirow{6}{*}{$0.75: 1$} & 0 & $18.5 \pm 0.3$ & $18.4 \pm 0.3$ & $18.7 \pm 0.4$ & $18.6 \pm 0.5$ \\
\hline & 5.0 & $13.3 \pm 0.2$ & $13.3 \pm 0.3$ & $13.2 \pm 0.1$ & $13.4 \pm 0.2$ \\
\hline & 10.0 & $9.6 \pm 0.2$ & $9.9 \pm 0.1$ & $9.3 \pm 0.3$ & $9.7 \pm 0.2$ \\
\hline & 15.0 & $5.6 \pm 0.1$ & $5.8 \pm 0.1$ & $5.5 \pm 0.2$ & $5.4 \pm 0.1$ \\
\hline & 20.0 & $4.4 \pm 0.1$ & $4.6 \pm 0.3$ & $4.4 \pm 0.2$ & $4.4 \pm 0.1$ \\
\hline & 25.0 & $3.4 \pm 0.1$ & $3.3 \pm 0.1$ & $3.2 \pm 0.1$ & $3.3 \pm 0.2$ \\
\hline \multirow{6}{*}{$0.83: 1$} & 0 & $18.5 \pm 0.2$ & $18.4 \pm 0.3$ & $18.7 \pm 0.3$ & $18.6 \pm 0.4$ \\
\hline & 5.0 & $14.8 \pm 0.3$ & $14.8 \pm 0.5$ & $14.3 \pm 0.4$ & $14.2 \pm 0.3$ \\
\hline & 10.0 & $10.2 \pm 0.3$ & $10.8 \pm 0.2$ & $10.4 \pm 0.2$ & $10.0 \pm 0.4$ \\
\hline & 15.0 & $5.6 \pm 0.1$ & $5.5 \pm 0.1$ & $5.8 \pm 0.1$ & $5.7 \pm 0.2$ \\
\hline & 20.0 & $2.5 \pm 0.1$ & $2.7 \pm 0.1$ & $2.5 \pm 0.1$ & $2.7 \pm 0.1$ \\
\hline & 25.0 & $2.3 \pm 0.1$ & $2.3 \pm 0.1$ & $2.3 \pm 0.1$ & $1.8 \pm 0.1$ \\
\hline \multirow{6}{*}{$0.92: 1$} & 0 & $18.5 \pm 0.4$ & $18.4 \pm 0.3$ & $18.7 \pm 0.4$ & $18.6 \pm 0.3$ \\
\hline & 5.0 & $13.1 \pm 0.2$ & $12.3 \pm 0.3$ & $12.4 \pm 0.4$ & $12.3 \pm 0.5$ \\
\hline & 10.0 & $8.4 \pm 0.2$ & $8.2 \pm 0.1$ & $8.4 \pm 0.1$ & $8.3 \pm 0.2$ \\
\hline & 15.0 & $5.1 \pm 0.2$ & $4.9 \pm 0.2$ & $5.0 \pm 0.3$ & $5.1 \pm 0.3$ \\
\hline & 20.0 & $3.1 \pm 0.1$ & $3.3 \pm 0.1$ & $3.1 \pm 0.1$ & $2.8 \pm 0.1$ \\
\hline & 25.0 & $2.2 \pm 0.1$ & $2.3 \pm 0.1$ & $2.5 \pm 0.1$ & $2.4 \pm 0.1$ \\
\hline
\end{tabular}


Table 9. Liquid resistance of the waterborne primer coatings.

\begin{tabular}{|c|c|c|c|c|c|}
\hline \multirow{2}{*}{$\begin{array}{l}\text { Core-Shell Ratio of } \\
\text { Microcapsules }\end{array}$} & \multirow{2}{*}{$\begin{array}{l}\text { Mass Fraction of } \\
\text { Microcapsules (\%) }\end{array}$} & \multicolumn{4}{|c|}{ Liquid Resistance (Level) } \\
\hline & & $\mathrm{NaCl}$ & Ethanol & Detergent & Red Ink \\
\hline \multirow{6}{*}{$0.42: 1$} & 0 & 1 & 1 & 1 & 3 \\
\hline & 5.0 & 1 & 1 & 1 & 1 \\
\hline & 10.0 & 1 & 1 & 1 & 1 \\
\hline & 15.0 & 1 & 1 & 1 & 1 \\
\hline & 20.0 & 1 & 1 & 1 & 1 \\
\hline & 25.0 & 1 & 3 & 1 & 3 \\
\hline \multirow{6}{*}{$0.50: 1$} & 0 & 1 & 1 & 1 & 3 \\
\hline & 5.0 & 1 & 1 & 1 & 1 \\
\hline & 10.0 & 1 & 1 & 1 & 1 \\
\hline & 15.0 & 1 & 1 & 1 & 1 \\
\hline & 20.0 & 1 & 1 & 1 & 2 \\
\hline & 25.0 & 1 & 3 & 1 & 3 \\
\hline \multirow{6}{*}{$0.58: 1$} & 0 & 1 & 1 & 1 & 3 \\
\hline & 5.0 & 1 & 1 & 1 & 1 \\
\hline & 10.0 & 1 & 1 & 1 & 1 \\
\hline & 15.0 & 1 & 1 & 1 & 1 \\
\hline & 20.0 & 1 & 1 & 1 & 2 \\
\hline & 25.0 & 1 & 2 & 2 & 3 \\
\hline \multirow{6}{*}{$0.67: 1$} & 0 & 1 & 1 & 1 & 3 \\
\hline & 5.0 & 1 & 1 & 1 & 1 \\
\hline & 10.0 & 1 & 1 & 1 & 1 \\
\hline & 15.0 & 1 & 1 & 1 & 1 \\
\hline & 20.0 & 1 & 1 & 1 & 1 \\
\hline & 25.0 & 1 & 2 & 1 & 3 \\
\hline \multirow{6}{*}{$0.75: 1$} & 0 & 1 & 1 & 1 & 3 \\
\hline & 5.0 & 1 & 1 & 1 & 2 \\
\hline & 10.0 & 1 & 1 & 1 & 2 \\
\hline & 15.0 & 1 & 1 & 1 & 2 \\
\hline & 20.0 & 1 & 1 & 1 & 2 \\
\hline & 25.0 & 1 & 1 & 1 & 2 \\
\hline \multirow{6}{*}{$0.83: 1$} & 0 & 1 & 1 & 1 & 3 \\
\hline & 5.0 & 1 & 1 & 1 & 2 \\
\hline & 10.0 & 1 & 1 & 1 & 2 \\
\hline & 15.0 & 1 & 1 & 1 & 2 \\
\hline & 20.0 & 1 & 3 & 2 & 2 \\
\hline & 25.0 & 1 & 3 & 1 & 3 \\
\hline \multirow{6}{*}{$0.92: 1$} & 0 & 1 & 1 & 1 & 3 \\
\hline & 5.0 & 1 & 1 & 1 & 2 \\
\hline & 10.0 & 1 & 1 & 1 & 2 \\
\hline & 15.0 & 1 & 1 & 1 & 2 \\
\hline & 20.0 & 1 & 1 & 1 & 2 \\
\hline & 25.0 & 1 & 2 & 1 & 3 \\
\hline
\end{tabular}

\subsection{Microstructure Analysis}

The optical and mechanical features of the investigated systems showed that the $0.67: 1$ microcapsules had a better effect on the comprehensive properties of the wooden surface waterborne primer. Figure 4 shows the SEM and optical microscopy images of the 0.67:1 microcapsules. The results reveal that most of the microcapsules display a spherical shape, with a relatively narrow distribution of the particle size.

Figure 5 includes SEM images taken for the waterborne primer coating with a different content of 0.67:1 microcapsules. The coating without microcapsules was found to be smooth, as was expected. Instead, the presence of particles with some degree of agglomeration was observed on the surface of the coating with the mass fractions of microcapsules of $5.0 \%$ and $10.0 \%$. When $25.0 \%$ microcapsules were added, the particles on the surface of the waterborne primer coating became more and more agglomerated. With the increase of the 
microcapsule content, the overall surface density of the particles increased obviously, with direct effects on the emphasis of the chromatic aberration, diminishing the glossiness of the coatings and also changing their mechanical properties $[35,36]$. When the mass fractions of the microcapsules were $0-10.0 \%$, the microcapsules dispersed evenly in the coating.

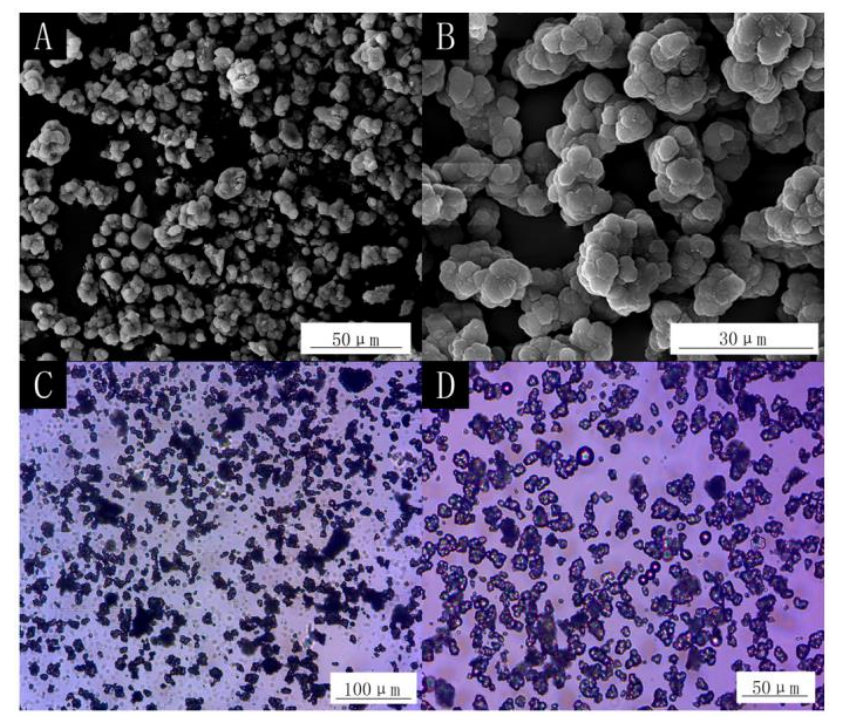

Figure 4. SEM and microscopic images of the microcapsules (the core-shell ratio is 0.67:1). SEM of (A) low magnification, and (B) high magnification, and optical microscopy images of (C) low magnification, and (D) high magnification.
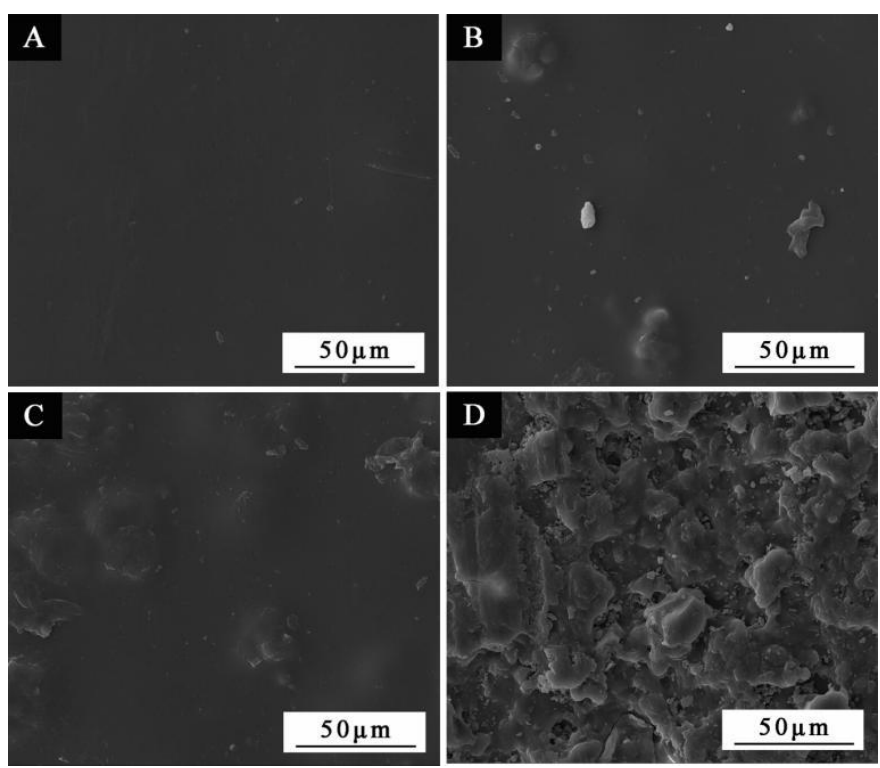

Figure 5. SEM of the waterborne primer coatings with different mass fractions of microcapsules (the core-shell ratio is $0.67: 1$ ): (A) 0; (B) $5.0 \%$; (C) $10.0 \%$; (D) $25.0 \%$.

Figure 6 shows the self-healing performance of the coating with the core-shell ratio of 0.67:1 microcapsules. We cut the coating with a blade and observed the healing effect of the coating at the same crack after 1 day and 3 days. It can be seen from the figure that the crack size at the same crack changed from the initial $20.71 \mu \mathrm{m}$ to $16.25 \mu \mathrm{m}$, which proved that the coating has a certain self-healing property for microcracks. 

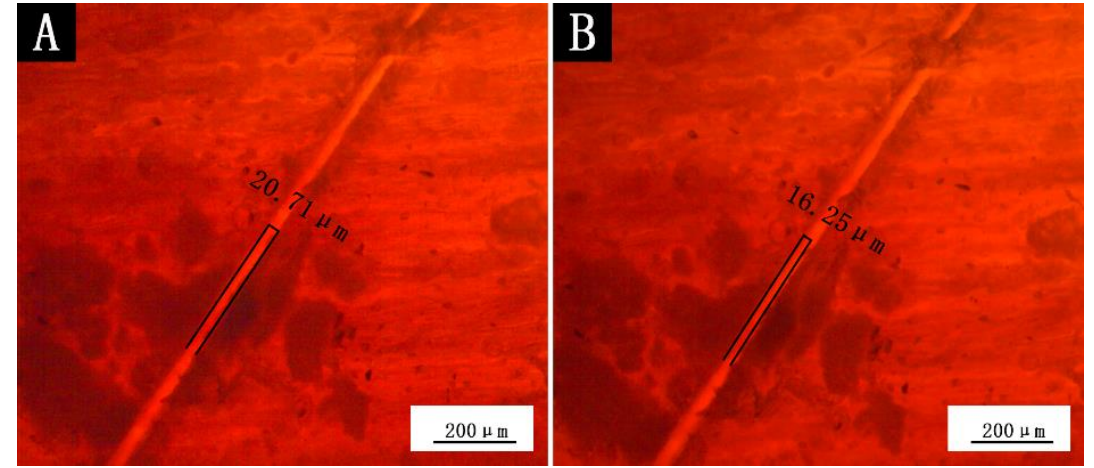

Figure 6. Testing of the self-healing properties of the coating (A) for 1 day and (B) for 3 days.

\subsection{Infrared Spectroscopy Analysis}

Figure 7 shows the infrared (IR) spectra of the waterborne primer coatings (with different contents of microcapsules of a 0.67:1 core-shell ratio). In the infrared spectrum of the microcapsule, the peaks at 3360,2929, 2865 and $1639 \mathrm{~cm}^{-1}$ were assigned to the vibrations of $\mathrm{N}-\mathrm{H}$ stretching, $\mathrm{C}-\mathrm{H}$ stretching (asymmetric and symmetric) and $\mathrm{C}=\mathrm{O}$ stretching, respectively, for the urea-formaldehyde resin representing the shell material. The vibration at $1730 \mathrm{~cm}^{-1}$ was ascribed to $\mathrm{C}=\mathrm{O}$ stretching in the $-\mathrm{COOH}$ groups belonging to the acrylic acid residues present in the structure of the waterborne primer entrapped in the microcapsules. In the infrared spectrum of the waterborne primer coating without microcapsules, the C-H stretching vibrations located at 2929 and $2865 \mathrm{~cm}^{-1}$ discussed above are also given by the $\mathrm{CH}_{2}$ groups of the polymeric component of the waterborne primer together with the stretching vibration at $1730 \mathrm{~cm}^{-1}$, which was attributed to the acrylic acid residues also present into the primer structure. The main component of the waterborne coating was waterborne acrylic acid copolymer dispersion. Because the main components of the microcapsules and primer coatings were very similar, the IR spectra in the fingerprint regions resemble each other.

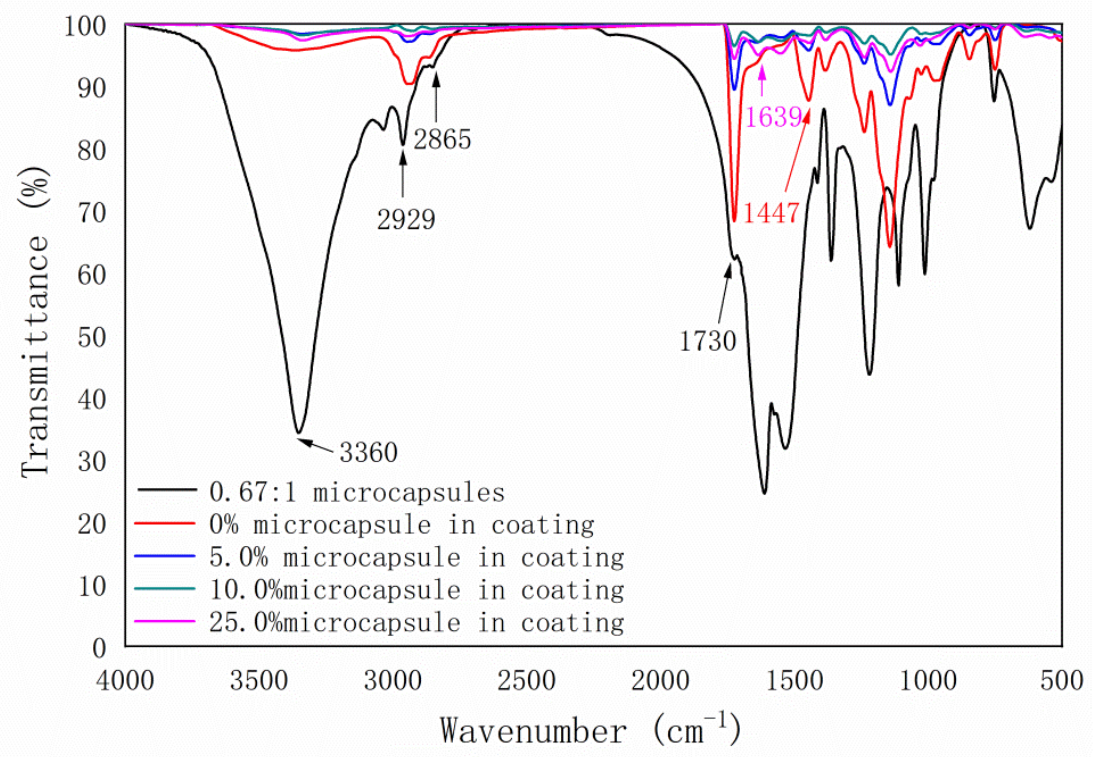

Figure 7. IR spectra of the waterborne primer coating with different mass fractions of microcapsules (the core-shell ratio is $0.67: 1$ ).

\section{Conclusions}

When the microcapsule mass fractions were between 0 and $10.0 \%$, the chromatic aberration ranged from 1.0 to 2.1. The coating glossiness decreased with the microcapsule 
mass fractions. The hardness of the coating was improved, rising to $3 \mathrm{H}$. When the coreshell ratios of the microcapsules were 0.58:1 and 0.67:1, and the mass fractions of the microcapsules were $0-20.0 \%$, the adhesion was also enhanced to grade $0-1$. Comparatively, the impact resistance increased for the coatings containing microcapsules with a core-shell ratio of $0.67: 1$. At the same time, for the coatings with $10.0-15.0 \%$ microcapsules of a $0.67: 1$ core-shell ratio, both the flexibility and elongation at the break reached the highest values. In line with the tendencies mentioned, the liquid resistance of these coatings was enhanced as well. The coating has a certain self-healing property for microcracks. Based on the comprehensive analysis, when the content of the microcapsules of $0.67: 1$ core-shell ratio was $10.0 \%$, the overall performance of the waterborne primer coating on the surface of the Basswood was the best, which provides a technical reference for the restraining of the surface crack of the wood coating.

Author Contributions: Conceptualization, methodology, validation, resources, data management and supervision, X.Y.; formal analysis, investigation, writing-review and editing, W.P. All authors have read and agreed to the published version of the manuscript.

Funding: This project was partly supported by the Natural Science Foundation of Jiangsu Province (BK20201386) and the Youth Science and Technology Innovation Fund of Nanjing Forestry University, Grant Number (CX2016018).

Institutional Review Board Statement: Not applicable.

Informed Consent Statement: Not applicable.

Data Availability Statement: Not applicable.

Conflicts of Interest: The authors declare no conflict of interest.

\section{References}

1. Jeong, H.; Lim, H.; Lee, D.Y.; Song, Y.S.; Kim, B.Y. Preparation and drug release behavior of nifedipine-loaded poly(lactic acid)/polyethylene glycol microcapsules. J. Nanosci. Nanotechnol. 2021, 21, 3735-3741. [CrossRef]

2. Li, Y.; Hao, P.W.; Zhang, M.Y. Fabrication, characterization and assessment of the capsules containing rejuvenator for improving the self-healing performance of asphalt materials: A review. J. Clean. Prod. 2021, 289, 125079. [CrossRef]

3. Ryu, S.J.; Bae, H.S. Properties analysis of crosslinked chitosan microcapsules by multiple emulsification method. Fash. Text. 2021 8, 1-14. [CrossRef]

4. Cotting, F.; Koebsch, A.; Aoki, I.V. Epoxy self-healing coating by encapsulated epoxy ester resin in poly (urea-formaldehydemelamine) microcapsules. Front. Mater. 2019, 6, 314. [CrossRef]

5. Tzavidi, S.; Zotiadis, C.; Porfyris, A.; Korres, D.M.; Vouyiouka, S. Epoxy loaded poly(urea-formaldehyde) microcapsules via in situ polymerization designated for self-healing coatings. J. Appl. Polym. Sci. 2020, 137, 43. [CrossRef]

6. Sun, D.W.; Yan, Z.; Lan, M.Z.; Wang, Z.M.; Cui, S.P.; Yang, J.L. Robust and impermeable metal shell microcapsules for onecomponent self-healing coatings. Appl. Surf. Sci. 2021, 546, 149114. [CrossRef]

7. Jiang, W.J.; Zhou, G.; Duan, J.J.; Liu, D.; Zhang, Q.T.; Tian, F.C. Synthesis and characterization of a multifunctional sustainedrelease organic-inorganic hybrid microcapsule with self-healing and flame-retardancy properties. ACS Appl. Mater. Interfaces 2021, 13, 15668-15679. [CrossRef] [PubMed]

8. Ning, K.; Loomans, B.; Yeung, C.; Li, J.; Yang, F.; Leeuwenburgh, S. Influence of microcapsule parameters and initiator concentration on the self-healing capacity of resin-based dental composites. Dent. Mater. 2021, 37, 403-412. [CrossRef] [PubMed]

9. Yan, X.X.; Chang, Y.J.; Qian, X.Y. Preparation and self-repairing properties of urea formaldehyde-coated epoxy resin microcapsules. Int. J. Polym. Sci. 2019, 2019, 7215783. [CrossRef]

10. Xu, W.; Fang, X.Y.; Han, J.T.; Wu, Z.H.; Zhang, J.L. Effect of coating thickness on sound absorption property of four wood species commonly used for piano soundboards. Wood Fiber. Sci. 2020, 52, 28-43. [CrossRef]

11. Liu, Q.Q.; Gao, D.; Xu, W. Effect of sanding processes on the surface properties of modified Poplar coated by primer compared with Mahogany. Coatings 2020, 10, 856. [CrossRef]

12. Herrera, R.; Muszynska, M.; Krystofiak, T.; Labidi, J. Comparative evaluation of different thermally modified wood samples finishing with UV-curable and waterborne coatings. Appl. Surf. Sci. 2015, 357, 1444-1453. [CrossRef]

13. Yan, X.X.; Wang, L. Preparation of shellac resin microcapsules coated with urea formaldehyde resin and properties of waterborne paint films for Tilia Amurensis Rupr. Membranes 2020, 10, 278. [CrossRef]

14. Bao, Y.; Yan, Y.; Chen, Y.; Ma, J.Z.; Zhang, W.B.; Liu, C. Facile fabrication of BTA@ZnO microcapsules and their corrosion protective application in waterborne polyacrylate coatings. Prog. Org. Coat. 2019, 136, 105233. [CrossRef] 
15. Chen, K.L.; Zhou, J.L.; Che, X.G.; Zhao, R.Y.; Gao, Q. One-step synthesis of core shell cellulose-silica/n-octadecane microcapsules and their application in waterborne self-healing multiple protective fabric coatings. J. Colloid Interface Sci. 2020, 566, 401-410. [CrossRef] [PubMed]

16. Li, Y.B.; Wu, L.; Weng, M.J.; Tang, B.S.; Lai, P.F.; Chen, J.C. Effect of different encapsulating agent combinations on physicochemical properties and stability of microcapsules loaded with phenolics of plum (Prunus salicina lindl.). Powder Technol. 2018, 340, $459-464$.

17. Wang, L.; Yan, X.X. Mechanical and optical properties of thermochromic reversible waterborne primer film on tilia europaea with 1,2-benzo-6-diethylaminofluorane based microcapsules. Polymers 2020, 12, 2062. [CrossRef]

18. Fu, H.; Gong, W.; Chen, B.B.; Chen, Y.X.; Ban, D.M.; Yin, X.G.; Pei, X.L.; He, L. Influence of electrolytes on thermal expansion microcapsules. J. Macromol. Sci. A 2019, 56, 104-114. [CrossRef]

19. Katoueizadeh, E.; Zebarjad, S.M.; Janghorban, K. Mechanical properties of epoxy composites embedded with functionalized urea-formaldehyde microcapsules containing an oxidizable oil. Mater. Chem. Phys. 2021, 260, 124106. [CrossRef]

20. Han, T.L.; Wang, X.F.; Li, D.W.; Li, D.F.; Xing, F.; Han, N.X. Influence of strain rate on mechanical characteristic and pore structure of self-healing cementitious composites with epoxy/urea-formaldehyde microcapsules. Constr. Build. Mater. 2021, $268,121138$. [CrossRef]

21. Li, Y.; Jiang, J.C.; Chen, Z.Q.; Chen, Z.W.; Ni, L. Preparation and characterization of microencapsulated aluminum hypophosphite and its performance on the thermal, flame retardancy, and mechanical properties of epoxy resin. Polym. Compos. 2021, 42, 1818-1834. [CrossRef]

22. Yan, X.X.; Zhao, W.T.; Qian, X.Y. Effect of urea-formaldehyde (UF) with waterborne emulsion microcapsules on properties of waterborne acrylic coatings based on coating process for American Lime. Appl. Sci. 2020, 10, 6341. [CrossRef]

23. Liu, W.L.; Zhang, J.P.; Liu, Q.; Pei, J.Z.; Zhu, C.Z.; Liu, P. Effects of emulsifier dosage and curing time on self-healing microcapsules containing rejuvenator and optimal dosage in asphalt binders. J. Nanosci. Nanotechnol. 2019, 19, 57-65. [CrossRef] [PubMed]

24. Hu, Y.D.; Li, C.N.; Wang, J.Y.; Jia, X.L.; Zhu, J.T.; Wang, Q.; Wang, H.; Yang, Y.J. Osmosis manipulable morphology and photonic property of microcapsules with colloidal nano-in-micro structure. J. Colloid Interface Sci. 2020, 574, 337-346. [CrossRef] [PubMed]

25. Wang, Y.D.; Wu, R.X.; Feng, M.C.; Zhang, G.X.; Zhang, C.C.; Hao, P.W. Synthesis of microcapsules with waste oil core and application in self-healing asphalt. Pet. Sci. Technol. 2019, 38, 203-209. [CrossRef]

26. Zhao, M.X.; Li, M.K.; Wang, L.; Zhang, X.; Kong, X.F. Preparation and characterization of paraffin@CLPS/MS phase change microcapsules for thermal energy storage. ChemistrySelect 2020, 5, 7190-7196. [CrossRef]

27. Neto, A.G.C.; Pellanda, A.C.; Jorge, A.R.D.; Floriano, J.B.; Berton, M.A.C. Preparation and evaluation of corrosion resistance of a self-healing alkyd coating based on microcapsules containing Tung oil. Prog. Org. Coat. 2020, 147, 105874. [CrossRef]

28. Amor, G.; Sabbah, M.; Caputo, L.; Idbella, M.; De Feo, V.; Porta, R.; Fechtali, T.; Mauriello, G. Basil essential oil: Composition, antimicrobial properties, and microencapsulation to produce active chitosan films for food packaging. Foods 2021, $10,121$. [CrossRef]

29. GB/T4893.4-2013 Physicochemical Performance Test of Furniture Surface Paint Film Part 4 Determination of Adhesion Cross-Cutting Method; Standardization Administration of the People's Republic of China: Beijing, China, 2013; pp. 1-4. (In Chinese)

30. GB/T4893.9-2013 Physical and Chemical Properties Test of Furniture Surface Paint Film Part 9 Determination of Impact Resistance; Standardization Administration of the People's Republic of China: Beijing, China, 2013; pp. 1-4. (In Chinese)

31. Du, W.; Yu, J.Y.; He, B.Y.; He, Y.H.; He, P.; Li, Y.; Liu, Q.T. Preparation and characterization of nano-SiO $2 / \mathrm{paraffin} / \mathrm{PE}$ wax composite shell microcapsules containing TDI for self-healing of cementitious materials. Constr. Build. Mater. 2020, 231, 117060. [CrossRef]

32. Chen, T.Q.; Fang, L.; Li, X.; Gao, D.S.; Lu, C.H.; Xu, Z.Z. Self-healing polymer coatings of polyurea-urethane/epoxy blends with reversible and dynamic bonds. Prog. Org. Coat. 2020, 147, 105876. [CrossRef]

33. Mohammadloo, H.E.; Mirabedini, S.M.; Pezeshk-Fallah, H. Microencapsulation of quinoline and cerium based inhibitors for smart coating application: Anti-corrosion, morphology and adhesion study. Prog. Org. Coat. 2019, 137, 105339. [CrossRef]

34. Kim, Y.N.; Nam, K.H.; Jung, Y.C.; Han, H. Interfacial adhesion and self-healing kinetics of multi-stimuli responsive colorless polymer bilayers. Compos. Part B Eng. 2020, 203, 108451. [CrossRef]

35. Han, T.L.; Wang, X.F.; Li, D.W.; Li, D.F.; Xing, F.; Han, N.X. Impermeability characteristics of cementitious materials with self-healing based on epoxy/urea-formaldehyde microcapsules using an immersion test. Constr. Build. Mater. 2020, $259,119782$. [CrossRef]

36. Nassho, Y.; Sanada, K. Microstructure optimizations for improving interlaminar shear strength and self-healing efficiency of spread carbon fiber/epoxy laminates containing microcapsules. J. Compos. Mater. 2021, 55, 27-38. [CrossRef] 